\title{
Allodynia in Cervical Polyradiculopathy Due to Low-voltage Electrical Burn Injury: A Case Report
}

\author{
Marian Michelle M. Marquez, PTRP, MD, Dorothy Dy Ching Bing-Agsaoay, MD, \\ Anna Cecilia S.A. Tiangco, MD and Carl Froilan D. Leochico, PTRP, MD \\ Department of Rehabilitation Medicine, Philippine General Hospital, University of the Philippines Manila
}

\begin{abstract}
Neuropathic pain has been described following an electrical injury, whether as an immediate response or a late-onset sequela. There is much information on high-voltage injuries in literature due to its dramatic presentation, but limited studies on low-voltage injuries. However, low-voltage injuries can be as diverse and may have symptoms varying from minimal cutaneous involvement to full-thickness injury. Significant injuries may result from multiple factors, including prolonged duration of exposure and a higher amount of current transmitted.

We illustrate an atypical presentation of a low-voltage injury in a 17-year-old female. The patient had a lowvoltage electrical injury with no cutaneous burn noted on the affected extremity. She initially presented with allodynia, which seemed disproportionate to the clinical findings expected in a low-voltage injury. The patient underwent an electrodiagnostic study, which showed cervical polyradiculopathy (C5, C6, C7 polyradiculopathy) and neuromusculoskeletal ultrasonology, which showed enlarged right C5 nerve root. Medical management, daily physical and occupational therapies, and psychological management, were instituted, which resulted in significant improvement of the patient's pain level and functional status.
\end{abstract}

We describe the importance of the multimodal approach (medical and rehabilitation) in managing this atypical case.

Keywords: electrical injury, allodynia, pain management, cervical polyradiculopathy, burn rehabilitation

\section{INTRODUCTION}

E-poster presented in the University of the Philippines - Philippine General Hospital $25^{\text {th }}$ Annual Research Week on November 16-20, 2020, at Ermita, Manila, Philippines.

Poster presented in the $14^{\text {th }}$ International Society of Physical and Rehabilitation Medicine (ISPRM) World Congress and Association of Academic Physiatrists (AAP) $5^{\text {th }}$ Annual Meeting on March 4-9, 2020, at Orlando, Florida, United States of America.

Poster presented in the Philippine Academy of Rehabilitation Medicine (PARM) $30^{\text {th }}$ Annual Convention, and awarded $1^{\text {st }}$ place Scientific Research Forum (Poster Category) on February 27, 2020, at the SMX Convention Center, Bacolod City, Philippines.

Paper presented in the University of the Philippines - Philippine General Hospital Department of Rehabilitation Medicine $19^{\text {th }}$ Post Graduate Course, and awarded $2^{\text {nd }}$ place, Interesting Case Presentation on October 25, 2019, at the Century Park Hotel, Malate, Manila, Philippines.

Corresponding author: Marian Michelle M. Marquez, PTRP, MD Department of Rehabilitation Medicine

Philippine General Hospital

University of the Philippines Manila

Taft Avenue, Ermita, Manila 1000, Philippines

Email: mmmarquez1@up.edu.ph
Neurological complications usually occur following severe electrical burns. "Electrical injuries are common in clinical practice because of the accidental exposure to low voltage $(<500 \mathrm{~V})$ domestic circuits". ${ }^{1}$ Peripheral mononeuropathies or polyneuropathies are common sequelae of electrical injury, with pain as the usual presenting chief complaint in $92.7 \%$ of cases. ${ }^{2}$ The most common complications following lowvoltage injuries are neurological. Following an electrical injury, typical symptoms of peripheral nerve injury reported were persistent numbness, tingling, and feeling of "still being electrocuted," as well as increasing pain. Still, limited studies point to or describe allodynia. ${ }^{3}$ Allodynia, defined as pain in response to a non-nociceptive stimulus, reserved to forms of pain that are caused by excitation of low-threshold sensory nerve fibers (e.g., dynamic tactile allodynia to tangential stroking stimuli, as in brushing the skin), or pain in response to non-nociceptive stimuli, is rarely seen or has been reported only in some cases of high-voltage electrical injury. ${ }^{4}$

This study describes an atypical case of a patient presenting with allodynia following a low-voltage electrical burn injury resulting in right cervical polyradiculopathy, the 
diagnostic tests, and medical and rehabilitation approach in management.

\section{Patient Information and Clinical Findings}

A 17-year-old female, right-handed, grade 12 student from Iguig, Cagayan, complained of pain after incurring a low-voltage electric injury on her right upper extremity when she accidentally held an exposed wire of a charger plugging it last September 10, 2018 (Figure 1). She gradually developed allodynia of the entire right upper extremity without any evidence of cutaneous injury, prompting consult and admission at a local hospital (in Cagayan) one-day post-injury. No risk factors for peripheral neuropathy were identified. With minimal pain relief, the patient was given pregabalin $75 \mathrm{mg} /$ tablet once a day and discharged after four days. Electromyography-nerve conduction velocity (EMG-NCV) study done two weeks after the injury showed typical results. She was maintained on pregabalin $75 \mathrm{mg} /$ tablet one tablet once a day but still with minimal relief of symptoms, leading to progressing inability to move the right upper extremity and difficulty in her ADLs. Repeat EMGNCV at two months post-injury (November 2018) showed suitable C5, C6, and C7 radiculopathy, incomplete, with acute and chronic denervation (Appendix 1).

At three months post-injury, we initially saw the patient at our institution's outpatient clinic, as they sought a second opinion due to the progression of her symptoms. She came in with a chief complaint of right upper extremity pain, described as pain even on light touch and pressure, leading to inability to move her right wrist and hand, elbow and shoulder. Systemic physical examination was unremarkable, except for sensory evaluation showing allodynia of the right upper extremity, shoulder, and neck, with a score of 10/10 on the numerical rating scale. No localizing signs were seen. On musculoskeletal evaluation, no gross deformity was seen on the cervical spine area, and no significant atrophy was appreciated upon inspection of the affected extremity. The patient winces in pain upon palpation of her right upper extremity, and muscle spasm was noted on her right upper trapezius area. Limitation of motion with muscle guarding was noted on her neck, right shoulder, elbow, wrist, and hand (Appendix 2). Manual muscle testing was not accurately assessed due to pain. On functional evaluation, the patient requires moderate assistance to supervision in her activities of daily living (ADLs) requiring movement and use of her right upper extremity, particularly in self-care (eating, grooming, upper and lower body dressing, and toileting) and in the toilet/tub transfers (Appendix 3). The patient was admitted to our institution's subacute burn rehabilitation ward for further evaluation and management.

\section{Diagnostic Assessment}

Musculoskeletal ultrasound scanning was done to visualize the cervical nerve roots and brachial plexus. Findings showed slight enlargement of the right $\mathrm{C} 5$ nerve
September 10, 2018

Day of Injury

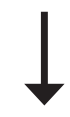

24 hours up to 2 weeks post-injury

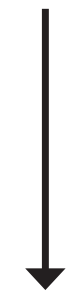

2 months post-injury

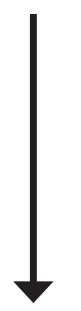

3 months post-injury

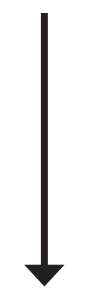

4 months post-injury

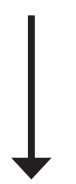

6 months post-injury

- No recurrence of symptoms

Legend: NRS - Numerical rating scale, ODHS - once a day at bedtime, ADLs - activities of daily living, UE - upper extremity, MSK-UTZ musculoskeletal ultrasound.

Figure 1. Timeline of patient's history, symptoms, diagnostics, and management.

root (encircled A) compared to the left (circled C); however, no uptake was seen on color Doppler (Figure 2).

Magnetic resonance imaging (MRI) of the cervical spine and right brachial plexus showed straightening of the cervical lordosis probably due to muscle spasm; otherwise, it is a negative MRI study of the cervical spine and brachial plexus, with no signs of nerve roots and brachial plexus edema or distortion (Figure 3). 


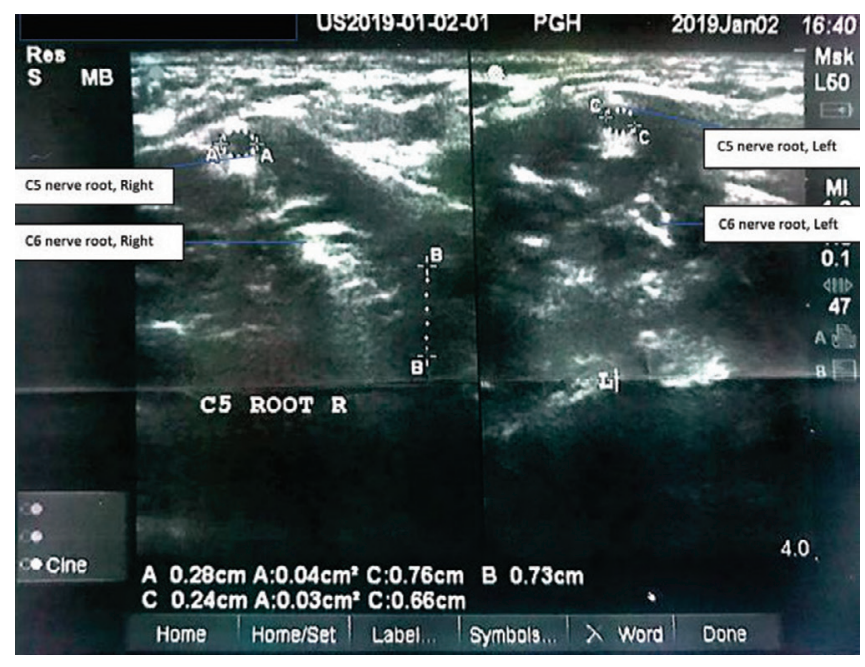

Figure 2. Musculoskeletal ultrasound image of the cervical nerve roots, transverse view (SAX), supraclavicular area, using a linear probe.

\section{THERAPEUTIC INTERVENTION}

\section{Medical Management}

The main goal of admission was to ensure adequate pain control through pain medications and pain modalities and improve the performance of activities of daily living (ADLs) (Table 1).

\section{Rehabilitation management}

The patient underwent daily, twice-a-day physical therapy (PT) and occupational therapy (OT) sessions during admission. A regimen of superficial heating/pain modalities and range of motion/strengthening exercises was done during PT and desensitization techniques and activities of daily living (ADL) retraining during OT. Deep breathing exercises and relaxation techniques were also done during the psychological therapy sessions.

Appendix 2 summarizes the manual muscle testing (MMT) and range of motion (ROM) scores. Muscle strength was documented from admission and upon discharge, with

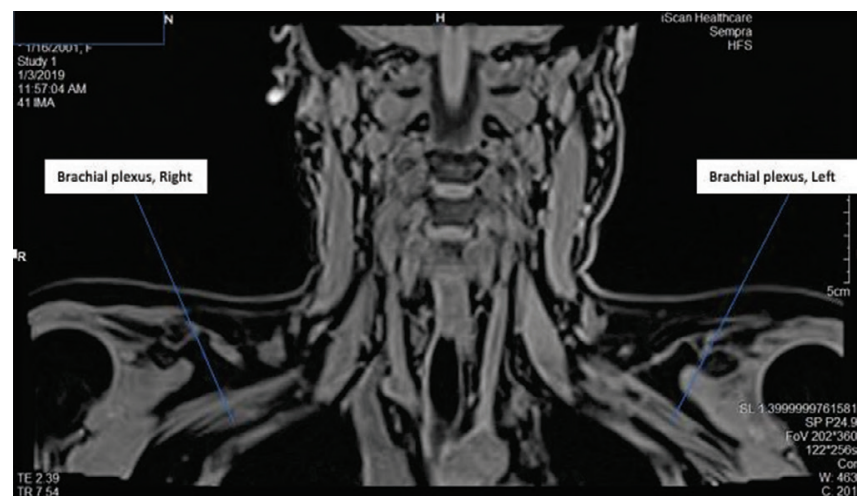

Figure 3. T2-weighted magnetic resonance imaging of the brachial plexus, coronal view.

notable improvements from gravity-assisted and anti-gravity motions (2-3/5) to tolerating moderate resistance (4/5). Range of motion was also measured weekly, noting gradual improvements particularly in cervical lateral flexion and rotation, shoulder flexion and abduction, and elbow flexion motions, and achieved full range of motion by discharge. Activities of daily living (ADLs), particularly self-care activities such as eating, grooming, bathing, upper and lower garment dressing, toileting, were monitored weekly using the Functional Independence Measure (FIM) Score. The patient was noted to be significantly improved, initially requiring minimal to moderate assistance in all self-care activities upon admission, to total independence upon discharge (Appendix 3).

\section{Follow-up and Outcomes}

Upon discharge, the patient completed a 2-week course of home medications and discontinued taking medicines after that. On follow-up one month after discharge, the patient was seen ambulatory, with no new subjective complaints of pain and hypersensitivity of the cervical and right upper extremity (score of $0 / 10$ on the numeric rating scale). The patient could move the cervical area and right upper extremity without limitations in movement (Appendix 2). No recurrence of symptoms was reported. EMG-NCV

Table 1. Summary of Medical Management and Rehabilitation Management

\begin{tabular}{|c|c|c|c|c|}
\hline Admission & Week 1 & Week 2 & Week 3 & Week 4 until Discharge \\
\hline \multicolumn{5}{|c|}{ Daily physical therapy (BID), occupational therapy, and psychology } \\
\hline Pregabalin 50mg TID & $\begin{array}{l}\text { Pregabalin } 100 \mathrm{mg} \text { AM, } \\
50 \mathrm{mg} \text { noon \& HS }\end{array}$ & $\begin{array}{l}\text { Pregabalin } 50 \mathrm{mg} \text { AM \& } \\
\text { noon, } 100 \mathrm{mg} \mathrm{HS}\end{array}$ & $\begin{array}{c}\text { Pregabalin 50mg AM \& } \\
\text { noon, } 100 \mathrm{mg} \mathrm{HS}\end{array}$ & Pregabalin 50mg 2 caps HS \\
\hline $\begin{array}{c}\text { Tramadol + Paracetamol } \\
37.5 / 325 \text { TID }\end{array}$ & $\begin{array}{c}\text { Tramadol + Paracetamol } \\
\text { 37.5/325 TID }\end{array}$ & $\begin{array}{c}\text { Tramadol + Paracetamol } \\
37.5 / 325 \text { TID }\end{array}$ & $\begin{array}{c}\text { Orphenadrine citrate }+ \\
\text { Paracetamol 50/650mg TID }\end{array}$ & $\begin{array}{c}\text { Orphenadrine citrate + } \\
\text { Paracetamol 50/650mg BID }\end{array}$ \\
\hline $\begin{array}{l}\text { UMP + Folic acid + } \\
\text { Vit B12 BID }\end{array}$ & $\begin{array}{l}\text { UMP + Folic acid + } \\
\text { Vit B12 BID }\end{array}$ & & & Agmatine sulfate 2 caps $\mathrm{HS}$ \\
\hline NRS $10 / 10$ & NRS $7 / 10$ & NRS 5-6/10 & NRS 3-5/10 & NRS 0-1/10 \\
\hline FIM Score: 100/126 & FIM Score $106 / 126$ & FIM Score: 106/126 & FIM Score: 126/126 & FIM Score: 126/126 \\
\hline
\end{tabular}

Legend: UMP - Uridine monophosphate, NRS - numerical rating scale, BID - twice a day, TID - 3 times a day, HS - at bedtime, FIM - Functional Independence Measure. NRS was taken at the end of the week after giving medications. 
Table 2. Electromyography results at 2 weeks, 2 months, and 6 months post-injury

\begin{tabular}{|c|c|c|c|c|c|c|c|c|}
\hline \multirow{2}{*}{ Side } & \multirow{2}{*}{ Muscle } & \multirow{2}{*}{ Nerve } & \multicolumn{2}{|c|}{2 weeks post-injury } & \multicolumn{2}{|c|}{2 months post-injury } & \multicolumn{2}{|c|}{4 months post-injury } \\
\hline & & & Fibs & Psw & Fibs & Psw & Fibs & Psw \\
\hline Right & Abductor Poll Brevis & Median & $\mathrm{Nml}$ & $\mathrm{Nml}$ & $\mathrm{Nml}$ & $\mathrm{Nml}$ & $\mathrm{Nml}$ & $\mathrm{Nml}$ \\
\hline Right & Biceps & Musculocut & $\mathrm{Nml}$ & $\mathrm{Nml}$ & $\mathrm{Nml}$ & $3+$ & $\mathrm{Nml}$ & $\mathrm{Nml}$ \\
\hline Right & Triceps & Radial & $\mathrm{Nml}$ & $\mathrm{Nml}$ & $\mathrm{Nml}$ & $3+$ & $\mathrm{Nml}$ & $\mathrm{Nml}$ \\
\hline Right & Deltoid & Axillary & $\mathrm{Nml}$ & $\mathrm{Nml}$ & $\mathrm{Nml}$ & $2+$ & $\mathrm{Nml}$ & $\mathrm{Nml}$ \\
\hline Right & Infraspinatus & SupraScap & $\mathrm{Nml}$ & $\mathrm{Nml}$ & $\mathrm{Nml}$ & $2+$ & $\mathrm{Nml}$ & $\mathrm{Nml}$ \\
\hline Right & Cervical Paraspinal Up & Rami (C5-C6) & $\mathrm{Nml}$ & $\mathrm{Nml}$ & $\mathrm{Nml}$ & $3+$ & $\mathrm{Nml}$ & $1+$ \\
\hline Right & Cervical Paraspinal Mid & Rami (C7) & $\mathrm{Nml}$ & $\mathrm{Nml}$ & $\mathrm{Nml}$ & $3+$ & $1+$ & $1+$ \\
\hline Right & Cervical Paraspinal Low & Rami (C8-T1) & $\mathrm{Nml}$ & $\mathrm{Nml}$ & $\mathrm{Nml}$ & $2+$ & $\mathrm{Nml}$ & $\mathrm{Nml}$ \\
\hline
\end{tabular}

Legend: Fibs - Fibrillation potentials, Psw - Positive sharp waves, Nml - Normal

study was repeated on the $4^{\text {th }}$-month post-injury. The NCV studies were still within normal limits. Electromyography findings showed right C5, C6, and C7 cervical radiculopathy, with acute denervation changes, with signs of reinnervation. Compared with the EMG-NCV studies done on the $2^{\text {nd }}$ week of injury and two months post-injury, the latest study showed significantly improved electromyographic findings (Table 2).

\section{DISCUSSION}

The extent of damage from electrical injury commonly ranges from mild superficial skin burns to severe multiple organ dysfunction and death. ${ }^{5}$ Neurologic impairment is not unusual and may be highly variable in clinical presentation. There have been limited reports of peripheral neuropathy after low-voltage injury and sporadic reports of delayed peripheral neuropathy similar to our patient's clinical manifestation. To our knowledge, no local studies have reported a case of polyradiculopathy with an absent cutaneous involvement in an electrical burn injury setting.

An initial inflammatory response, minutes after an electrical injury, leads to the release of numerous chemical irritants that, for several days, sensitize and stimulate the nociceptors. The quality of pain changes as the inflammatory response subsides, but there may be a disorderly regeneration of nerve tissue, predisposing to neuropathic pain. ${ }^{6}$ Delayed neurological manifestations, including complex regional pain syndrome (CRPS), predominate during the chronic phase after an electrical injury, characterized by pain, swelling, vasomotor changes, allodynia, and regional osteoporosis. ${ }^{1}$ In the case of our patient, no vasomotor changes were present during the initial examination and admission, and no signs of regional osteoporosis were seen.

Given the unique pathophysiology of electrical injuries, the combination of medications used for pain management is often needed to be modified as patients develop tolerance to drugs. Pregabalin has been shown in multiple studies to be an effective analgesic agent in both peripheral and central neuropathic pain. It effectively reduces post-burn pain by inhibiting neuronal excitability, especially in the central nervous system. ${ }^{7}$ Opiates provide excellent analgesia but include clinically relevant side effects such as respiratory depression, itch, nausea, and vomiting. ${ }^{8}$ Meanwhile, nonsteroidal anti-inflammatory drugs (NSAIDs) offer effective analgesic, anti-inflammatory properties, and antipyretic effects. Still, they cannot be recommended for routine use in patients with significant burn injuries due to the already increased risk of renal failure and peptic ulceration. ${ }^{8}$ Auxiliary therapy, including a combination of uridine monophosphate with folic acid and vitamin B12, has been indicated to treat neuropathic pain with peripheral nervous system lesions, aiding in neuronal and axonal regeneration. ${ }^{9}$ Combined pain pharmacotherapy such as the fixed-dose combination of NSAIDs and spasmolytics (Orphenadrine citrate) has been beneficial in treating muscular pains and neuralgia and has been noted to improve the response in people with insufficient monotherapy. ${ }^{10}$ Agmatine has been demonstrated to reduce pain-associated behaviors due to mechanisms involving neuromodulation. ${ }^{11}$

Peripheral neuropathy is the most frequent disabling neuromuscular complication of major burn injury. ${ }^{12}$ As our patient manifested with neuropathic symptoms, electrodiagnostic studies were instituted to document and monitor the pattern and extent of the injury. A study done by Tamam et al. in 2013 showed that $7 \%$ of all burn patients in their institution were diagnosed with peripheral neuropathy (mononeuropathy > polyneuropathy) and were all subjected to electrodiagnostic studies. Although, it was not specified in the study whether the burn injury was low-voltage or highvoltage in etiology. Meanwhile, limited studies show the utility of ultrasonography, particularly for the assessment of electrical injury-induced neuropathy. Still, its use is gaining popularity in the evaluation of cervical radiculopathy and entrapment neuropathies. Ultrasonography has shown a diagnostic value in assessing cervical radiculopathy, showing the cross-sectional areas of the affected nerve roots to be significantly enlarged. ${ }^{13}$

A study by Li, Gomez, and Fish in 2010 illustrated the extent of chronic pain that some electrically injured patients endure and how a multimodal approach to pain management is required. Rehabilitation for electrical burn injuries requires 
an interdisciplinary approach. There is no single or ideal method to follow, as burn injury sequelae and complications can be variable and diverse. ${ }^{14}$ Massage therapy, acupuncture, heat and cold treatment, cognitive behavioral therapy were only some of the nonpharmacological modalities used in studies. Still, our approach to our patient was mainly based on her activity limitations and functional restrictions.

Our patient responded to a multimodal approach, making way for a complete functional recovery and no recurrence of symptoms after that.

\section{Patient's Perspective}

"The thing I have learned from this experience is that, don't underestimate an injury just because there is no physical evidence or obvious wound. I have never experienced that type of pain before, the unexplainable feeling of pain on my arms and hands even on the slightest and mildest touch. It affected my activities at home and school. I didn't imagine that what I thought was a simple electrical shock would render me unable to move my arm for almost six months. I believe that not only the medications, but the continuous therapy that I received, has greatly contributed to the process of my recovery."

\section{CONCLUSION}

Following a low-voltage electrical injury, the patient presented with an atypical course of neuropathy characterized as allodynia. Her symptoms seemed disproportionate to the diagnostic results and usual presentation of cervical polyradiculopathy. The comprehensive medical and rehabilitation approach emphasizes the importance of combining various treatment modalities that will address the specific needs of these patients. The use of ultrasonography in this study showed that it could be a convenient and valuable imaging modality in detecting peripheral nerve pathologies brought about by electrical injury-induced neuropathy.

\section{Consent to Participate}

The mother of the patient gave informed written consent for the publication of this report.

\section{Statement of Authorship}

All authors participated in the data collection and analysis and approved the final version submitted.

\section{Author Disclosure}

All authors declared no conflicts of interest.

\section{Funding Source}

The authors funded this paper. No external funding agency was involved.

\section{REFERENCES}

1. Ahmad FMH, Kumar KVSH. Failure to Fire after an Electrical Injury - A Complex Syndrome in a Soldier. Mil Med Res. 2015;2(1):2-5.

2. Wesner ML, Hickie J. Long-term Sequelae of Electrical Injury. Can Fam Physician. 2013;59(9):935-9.

3. Smith MA, Muehlberger T, Dellon AL. Peripheral Nerve Compression Associated with Low-voltage Electrical Injury without Associated Significant Cutaneous Burn. 2001;137-44.

4. Sandkühler J. Models and Mechanisms of Hyperalgesia and Allodynia. Physiol Rev [Internet]. 2009 Apr [cited 2019 Aug 2];89(2): 707-58. Available from: http://www.physiology.org/doi/10.1152/ physrev.00025.2008.

5. Schaefer NR, Yaxley JP, O’Donohue P, Lisec C, Jeyarajan E. Electrical Burn Causing a Unique Pattern of Neurological Injury. Plast Reconstr Surg - Glob Open. 2015;3(4):1-3.

6. Castro RJA de, Leal PC, Sakata RK. Pain Management in Burn Patients. Brazilian J Anesthesiol (English Ed) [Internet]. 2013 Jan 2 [cited 2019 Jul 31];63(1):149-53. Available from: https://www. sciencedirect.com/science/article/pii/S0104001413000298.

7. Jones LM, Uribe A, Cofer R. Pregabalin in the Reduction of Pain and Opioid Consumption after Burn Injuries. Medicine 2019; 98(18):1-8.

8. Richardson P, Mustard L. The Management of Pain in Burns Unit. Burns, 35 (2009), 921-36.

9. Rushai AK, Bogdanova LV, Klymovytskyy FV, Lisunov SV. Early Complex Rehabilitation Treatment of Patients with Fracture of Distal Metaepiphysis of The Radius. Medical Science of Ukraine. 2020;16(2):23-8.

10. Janczura M, Kobus-Moryson M, Sip S, Zarowski M; Nczak AW, Cielecka-Piontek J. Clinical Medicine Fixed-Dose Combination of NSAIDs and Spasmolytic Agents in the Treatment of Different Types of Pain-A Practical Review. J Clin Med. 2021;10:3118.

11. Laube G, Bernstein H. Agmatine: Multifunctional Arginine Metabolite and Magic Bullet in Clinical Neuroscience? Biochemical Journal. 2017;474 2619-40.

12. Tamam Y, Tamam C, Tamam B, Ustundag M, Orak M, Tasdemir N. Peripheral Neuropathy after Burn Injury. Eur Rev Med Pharmacol Sci. 2013;17 Suppl 1(Suppl 1):107-11.

13. Takeuchi M, Wakao N, Hirasawa A, Murotani K, Kamiya M, Osuka $\mathrm{K}$, et al. Ultrasonography Has a Diagnostic Value in the Assessment of Cervical Radiculopathy: A Prospective Pilot Study. Eur Radiol. 2017;27:3467-73.

14. Li ALK, Gomez M, Fish JS. Effectiveness of Pain Management following Electrical Injury. J Burn Care Res. 2010;31(1):73-82. 


\section{APPENDICES}

Appendix 1. EMG-NCV studies at 2 months post-injury (November 1, 2018)

\begin{tabular}{|c|c|c|c|c|c|c|c|c|c|c|c|}
\hline Stim Site & NR & $\begin{array}{l}\text { Peak } \\
\text { (ms) }\end{array}$ & $\begin{array}{c}\text { Norm } \\
\text { Peak (ms) }\end{array}$ & $\begin{array}{c}\text { P-T Amp } \\
(\mu \mathrm{V})\end{array}$ & $\begin{array}{c}\text { Norm P-T } \\
\text { Amp }\end{array}$ & Site1 & Site2 & $\begin{array}{c}\text { Delta-P } \\
\text { (ms) }\end{array}$ & Dist $(\mathrm{cm})$ & $\operatorname{Vel}(\mathrm{m} / \mathrm{s})$ & $\begin{array}{c}\text { Norm Vel } \\
(\mathrm{m} / \mathrm{s})\end{array}$ \\
\hline \multicolumn{12}{|c|}{ Left Ulnar Anti Sensory (5 $5^{\text {th }}$ Digit) } \\
\hline Wrist & & 2.9 & $<3.7$ & 69.5 & $>15.0$ & Wrist & $5^{\text {th }}$ Digit & 2.9 & 14.0 & 48 & $>38$ \\
\hline \multicolumn{12}{|c|}{ Right Ulnar Anti Sensory (5 $5^{\text {th }}$ Digit) } \\
\hline Wrist & & 2.8 & $<3.7$ & 75.0 & $>15.0$ & Wrist & $5^{\text {th }}$ Digit & 2.8 & 14.0 & 50 & $>38$ \\
\hline \multicolumn{12}{|c|}{ Motor Summary Table } \\
\hline Stim Site & NR & $\begin{array}{c}\text { Onset } \\
\text { (ms) }\end{array}$ & $\begin{array}{c}\text { Norm } \\
\text { Onset (ms) }\end{array}$ & $\begin{array}{l}\text { O-P Amp } \\
(\mathrm{mV})\end{array}$ & $\begin{array}{c}\text { Norm O-P } \\
\text { Amp }\end{array}$ & Site1 & Site2 & $\begin{array}{c}\text { Delta-0 } \\
\text { (ms) }\end{array}$ & Dist $(\mathrm{cm})$ & $\operatorname{Vel}(\mathrm{m} / \mathrm{s})$ & $\begin{array}{c}\text { Norm Vel } \\
(\mathrm{m} / \mathrm{s})\end{array}$ \\
\hline \multicolumn{12}{|c|}{ Left Median Motor (Abd Poll Brev) } \\
\hline Wrist & & 2.8 & $<4.2$ & 8.3 & $>5$ & Elbow & Wrist & 3.1 & 18.0 & 58 & $>50$ \\
\hline Elbow & & 5.9 & & 7.9 & & & & & & & \\
\hline \multicolumn{12}{|c|}{ Right Median Motor (Abd Poll Brev) } \\
\hline Wrist & & 3.0 & $<4.2$ & 8.3 & $>5$ & Elbow & Wrist & 3.1 & 18.0 & 58 & $>50$ \\
\hline Elbow & & 6.1 & & 7.9 & & & & & & & \\
\hline \multicolumn{12}{|c|}{ Left Ulnar Motor (Abd Dig Minimi) } \\
\hline Wrist & & 2.7 & $<4.2$ & 5.4 & $>3$ & B Elbow & Wrist & 2.8 & 17.0 & 61 & $>53$ \\
\hline B Elbow & & 5.5 & & 3.5 & & & & & & & \\
\hline \multicolumn{12}{|c|}{ Right Ulnar Motor (Abd Dig Minimi) } \\
\hline Wrist & & 2.6 & $<4.2$ & 6.1 & $>3$ & B Elbow & Wrist & 2.8 & 17.0 & 61 & $>53$ \\
\hline B Elbow & & 5.4 & & 2.6 & & & & & & & \\
\hline
\end{tabular}

\section{Comparison Summary Table}

\begin{tabular}{|c|c|c|c|c|c|c|c|c|}
\hline Stim Site & NR & Peak (ms) & Norm Peak (ms) & P-T Amp $(\mu \mathrm{V})$ & Site1 & Site2 & Delta-P (ms) & Norm Delta (ms) \\
\hline \multicolumn{9}{|c|}{ Left Median/Radial Dig I Comparison (Digit 1 - 10cm) } \\
\hline Median & & 2.3 & $<2.9$ & 148.3 & \multirow[t]{2}{*}{ Median } & \multirow[t]{2}{*}{ Radial } & \multirow[t]{2}{*}{0.1} & \multirow[t]{2}{*}{$<0.4$} \\
\hline Radial & & 2.2 & $<2.8$ & 22.2 & & & & \\
\hline \multicolumn{9}{|c|}{ Right Median/Radial Dig I Comparison (Digit 1 - 10cm) } \\
\hline Median & & 2.3 & $<2.9$ & 120.5 & \multirow[t]{2}{*}{ Median } & \multirow[t]{2}{*}{ Radial } & \multirow[t]{2}{*}{0.1} & \multirow[t]{2}{*}{$<0.4$} \\
\hline Radial & & 2.4 & $<2.8$ & 23.9 & & & & \\
\hline
\end{tabular}

\section{F Wave Studies}

\section{NR F-Lat (ms) Lat Norm (ms) L-R F-Lat (ms) L-R Lat Norm}

Left Median (Mrkrs) (Abd Poll Brev)

\begin{tabular}{|c|c|c|c|}
\hline 23.44 & $<33$ & 0.06 & $<2.2$ \\
\hline \multicolumn{4}{|c|}{ Right Median (Mrkrs) (Abd Poll Brev) } \\
\hline 23.38 & $<33$ & 0.06 & $<2.2$ \\
\hline
\end{tabular}

\begin{tabular}{|c|c|c|c|c|c|c|c|c|c|c|c|}
\hline Side & Muscle & Nerve & Ins Act & Fibs & Psw & Amp & Dur & Poly & Recrt & Int Pat & Comment \\
\hline Right & Abd Poll Brev & Median & $\mathrm{Nml}$ & $\mathrm{Nml}$ & $\mathrm{Nml}$ & $\mathrm{Nml}$ & $\mathrm{Nml}$ & 0 & $\mathrm{Nml}$ & $\mathrm{Nml}$ & \\
\hline Right & Biceps & Musculocut & $\mathrm{Nml}$ & $\mathrm{Nml}$ & $3+$ & $\mathrm{Nml}$ & $\mathrm{Nml}$ & 0 & $\mathrm{Nml}$ & $\mathrm{Nml}$ & \\
\hline Right & Triceps & Radial & $\mathrm{Nml}$ & $\mathrm{Nml}$ & $3+$ & $\mathrm{Nml}$ & $\mathrm{Nml}$ & 0 & $\mathrm{Nml}$ & $\mathrm{Nml}$ & \\
\hline Right & Deltoid & Axillary & $\mathrm{Nml}$ & $\mathrm{Nml}$ & $2+$ & $\mathrm{Nml}$ & $\mathrm{Nml}$ & 0 & $\mathrm{Nml}$ & $\mathrm{Nml}$ & \\
\hline Right & Infraspinatus & SupraScap & $\mathrm{Nml}$ & $\mathrm{Nml}$ & $2+$ & $\mathrm{Nml}$ & $\mathrm{Nml}$ & 0 & $\mathrm{Nml}$ & $\mathrm{Nml}$ & \\
\hline Right & Cervical Parasp Up & Rami & $\mathrm{Nml}$ & $\mathrm{Nml}$ & $3+$ & $\mathrm{Nml}$ & $\mathrm{Nml}$ & 0 & $\mathrm{Nml}$ & $\mathrm{Nml}$ & + CRDs \\
\hline Right & Cervical Parasp Mid & Rami & $\mathrm{Nml}$ & $\mathrm{Nml}$ & $3+$ & $\mathrm{Nml}$ & $\mathrm{Nml}$ & 0 & $\mathrm{Nml}$ & $\mathrm{Nml}$ & \\
\hline Right & Cervical Parasp Low & Rami & $\mathrm{Nml}$ & $\mathrm{Nml}$ & $2+$ & $\mathrm{Nml}$ & $\mathrm{Nml}$ & 0 & $\mathrm{Nml}$ & $\mathrm{Nml}$ & \\
\hline
\end{tabular}

NR F-Lat (ms) Lat Norm (ms) L-R F-Lat (ms) L-R Lat Norm Left Ulnar (Mrkrs) (Abd Dig Min)

\begin{tabular}{rrrr}
24.02 & $<36$ & 1.94 & $<2.5$ \\
\hline Right Ulnar (Mrkrs) (Abd Dig Min) & & \\
22.08 & $<36$ & 1.94 & $<2.5$ \\
\hline
\end{tabular}

Legend: Ins Act - Insertional activity, Fibs - Fibrillation potentials, Psw - positive sharp waves, Amp - amplitude, Dur - Duration, Poly - Polyphasia, Recrt - recruitment, Int Pat - Interference pattern 
Appendix 2. Summary of range of motion and muscle strength from admission to discharge

\begin{tabular}{|c|c|c|c|c|c|c|c|c|c|c|}
\hline \multirow{2}{*}{ Normal Range of Motion (ROM) } & \multicolumn{3}{|c|}{ Admission } & \multicolumn{2}{|c|}{ Week $1 \&$ Week 2} & \multicolumn{2}{|c|}{ Week 3} & \multicolumn{3}{|c|}{ Week 4 till discharge } \\
\hline & Active & Passive & MMT & Active & Passive & Active & Passive & Active & Passive & MMT \\
\hline Cervical flexion 0-45 & $0-45$ & $0-45$ & $4 / 5$ & $0-45$ & $0-45$ & $0-45$ & $0-45$ & $0-45$ & $0-45$ & $4 / 5$ \\
\hline Cervical extension 0-45 & $0-45$ & $0-45$ & $4 / 5$ & $0-45$ & $0-45$ & $0-45$ & $0-45$ & $0-45$ & $0-45$ & $4 / 5$ \\
\hline Cervical Lateral flexion 0-45 & $\begin{array}{l}\text { L } 0-30 \\
\text { R 0-50 }\end{array}$ & $\begin{array}{l}\text { L } 0-50 \\
\text { R } 0-50\end{array}$ & $3 / 5$ & $\begin{array}{l}\text { L } 0-30 \\
\text { R } 0-50\end{array}$ & $\begin{array}{l}\text { L } 0-50 \\
\text { R } 0-50\end{array}$ & $\begin{array}{l}\text { L } 0-30 \\
\text { R } 0-50\end{array}$ & $\begin{array}{l}\text { L } 0-50 \\
\text { R } 0-50\end{array}$ & $\begin{array}{l}\text { L } 0-50 \\
\text { R } 0-50\end{array}$ & $\begin{array}{l}\text { L } 0-50 \\
\text { R } 0-50\end{array}$ & $4 / 5$ \\
\hline Cervical rotation 0-60 & $\begin{array}{l}\text { L } 0-45 \\
\text { R } 0-50\end{array}$ & $\begin{array}{l}\text { L } 0-50 \\
\text { R } 0-50\end{array}$ & $3 / 5$ & $\begin{array}{l}\text { L } 0-45 \\
\text { R 0-50 }\end{array}$ & $\begin{array}{l}\text { L } 0-50 \\
\text { R } 0-50\end{array}$ & $\begin{array}{l}\text { L } 0-45 \\
\text { R 0-50 }\end{array}$ & $\begin{array}{l}\text { L } 0-50 \\
\text { R } 0-50\end{array}$ & $\begin{array}{l}\text { L } 0-50 \\
\text { R 0-50 }\end{array}$ & $\begin{array}{l}\text { L } 0-50 \\
\text { R } 0-50\end{array}$ & $4 / 5$ \\
\hline Shoulder flexion 0-180 & $0-90$ & $0-120$ & $2 / 5$ & $0-90$ & $0-120$ & $0-90$ & $0-120$ & $0-180$ & $0-180$ & $4 / 5$ \\
\hline Shoulder abduction 0-180 & $0-90$ & $0-120$ & $2 / 5$ & $0-90$ & $0-120$ & $0-90$ & $0-120$ & $0-180$ & $0-180$ & $4 / 5$ \\
\hline Shoulder extension 0-60 & $0-45$ & $0-45$ & $2 / 5$ & $0-45$ & $0-45$ & $0-45$ & $0-45$ & $0-45$ & $0-45$ & $4 / 5$ \\
\hline Elbow flexion 0-150 & $0-140$ & $0-140$ & $2 / 5$ & $0-140$ & $0-140$ & $0-140$ & $0-140$ & $0-140$ & $0-150$ & $4 / 5$ \\
\hline Wrist Extension 0-80 & $0-80$ & $0-80$ & $3 / 5$ & $0-80$ & $0-80$ & $0-80$ & $0-80$ & $0-80$ & $0-80$ & $4 / 5$ \\
\hline Wrist Flexion 0-80 & $0-90$ & $0-90$ & $3 / 5$ & $0-90$ & $0-90$ & $0-90$ & $0-90$ & $0-90$ & $0-90$ & $4 / 5$ \\
\hline MCP flexion $1^{\text {st }}-5^{\text {th }} 0-90$ & $0-90$ & $0-90$ & $3 / 5$ & $0-90$ & $0-90$ & $0-90$ & $0-90$ & $0-90$ & $0-90$ & $4 / 5$ \\
\hline PIP flexion $1^{\text {st }}-5^{\text {th }} 0-100$ & $0-80$ & $0-90$ & $3 / 5$ & $0-80$ & $0-90$ & $0-80$ & $0-90$ & $0-80$ & $0-90$ & $4 / 5$ \\
\hline DIP flexion $1^{\text {st }}-5^{\text {th }} 0-90$ & $0-90$ & $0-90$ & $3 / 5$ & $0-90$ & $0-90$ & $0-90$ & $0-90$ & $0-90$ & $0-90$ & $4 / 5$ \\
\hline
\end{tabular}

Legend: Range of Motion (ROM) measured in degrees, normal values based on American Association of Orthopedic Surgeons (AAOS). Manual manual testing (MMT) measured in scale up to $5 / 5$.

Appendix 3. Summary of Functional Independence Measure (FIM) score during management

\section{Activities of Daily Living Upon admission Week 1 and 2 Week 3 Week 4 up to discharge On follow-up after 1 month} Self Care

\begin{tabular}{llllll} 
A. Eating & 4 & 5 & 6 & 7 & 7 \\
B. Grooming & 4 & 5 & 6 & 7 & 7 \\
C. Bathing & 3 & 4 & 5 & 7 & 7 \\
D. Dressing: upper body & 3 & 4 & 6 & 7 & 7 \\
E. Dressing: lower body & 3 & 4 & 6 & 7 & 7 \\
F. Toileting & 3 & 4 & 5 & 7 & 7 \\
\hline
\end{tabular}

\section{Sphincter control}

\begin{tabular}{llllll} 
G. Bladder management & 7 & 7 & 7 & 7 & 7 \\
H. Bowel management & 7 & 7 & 7 & 7 & 7 \\
\hline
\end{tabular}

\section{Transfers}

\begin{tabular}{|c|c|c|c|c|c|}
\hline I. Bed, chair, wheelchair & 7 & 7 & 7 & 7 & 7 \\
\hline J. Toilet & 5 & 5 & 6 & 7 & 7 \\
\hline K. Tub, shower & 5 & 5 & 6 & 7 & 7 \\
\hline \multicolumn{6}{|l|}{ Locomotion } \\
\hline L. Walk/wheelchair & 7 & 7 & 7 & 7 & 7 \\
\hline M. Stairs & 7 & 7 & 7 & 7 & 7 \\
\hline Motor Subtotal Rating & 65 & 71 & 81 & 91 & 91 \\
\hline
\end{tabular}

\begin{tabular}{llllll}
\hline Motor Subtotal Rating & 65 & 71 & 81 & 91 & 91 \\
\hline Communication & & & & & 7 \\
N. Comprehension & 7 & 7 & 7 & 7 & 7 \\
O. Expression & 7 & 7 & 7 & 7 & 7 \\
\hline
\end{tabular}

\section{Social Cognition}

\begin{tabular}{lccccc} 
P. Social interaction & 7 & 7 & 7 & 7 & 7 \\
Q. Problem-solving & 7 & 7 & 7 & 7 & 7 \\
R Memory & 7 & 7 & 35 & 35 & 35 \\
\hline Cognitive Subtotal Rating & 35 & $106 / 126$ & $116 / 126$ & $126 / 126$ & $126 / 126$ \\
\hline Total & $100 / 126$ & 126 & 75 \\
\hline
\end{tabular}

Legend: FIM Scores 7 - Complete independence, 6 - Modified independence, 5 - Supervision (subject 100\%), 4 - Minimal assistance (subject 75\% or more), 3 - moderate assistance (subject $50 \%$ or more), 2 - maximal assistance (subject 25\% or more), 1 - total assistance (subject less than $25 \%$ ) 